\title{
Robert Cockburn Mossman
}

Robert Cockburn Mossman was born in Edinburgh in 1870 , and was educated at the Royal High School of the city. He was elected a Fellow of the Society in I891 and died at Buenos Aires on July 19, 1940.

From an early age his main interest in life was the study of meteorology, more especially in its climatological aspects. $\mathrm{He}$ began by compiling a weather record for Edinburgh, based on his own observations during the years $1886-1900$. This brought him into touch with $\mathrm{Dr}$ Alexander Buchan, the well-known meteorologist, who gave him every encouragement in his study of the science. It also led to his frequent employment as assistant at Ben Nevis Observatory, where he made a special study of weather phenomena in Glen Nevis. In 1902, he was appointed meteorological observer on the Scotia, the ship in which Dr W. S. Bruce led the Scottish Antarctic Expedition, 1902-5. In 1906 and 1907 he visited Spitzbergen and the Greenland Sea.

While on the Scotia expedition, Mossman had visited Laurie Island in the South Orkneys, and had established a temporary weather station on the island. This was afterwards taken over by the Argentine Government, and the relations so established led to his appointment in the Argentine meteorological service. In this he remained, with the exception of a break from I9I 3 to 1920 , until 1938 , being chiefly concerned with the climatological records compiled by the department.

Mossman's papers on Climatology are very numerous, reaching close on a hundred. They began with studies of the climates of Edinburgh and London, but his special opportunities led to the compilation of many papers on the climate of the Argentine and of the Antarctic. His papers are almost wholly confined to statistical results, and are well known for the care with which these have been compiled and presented.

In recognition of his work in the Antarctic, Mossman was awarded the Gold Medal of the Royal Scottish Geographical Society in 1905, and the Keith Prize of the Royal Society of Edinburgh in 1918.

A. C. M. 